\title{
SENTIDO, CONTENIDO Y MUTACIONES DE LA FRONTERA NORTE DE GRECIA*
}

\author{
Por \\ Dora Lafazani**
}

\begin{abstract}
RESUMEN
En este artículo se realiza un breve repaso de las implicaciones étnico culturales, económicas y políticas que definieron la frontera norte de Grecia, creada en 1913. Se pretende resaltar los rasgos determinantes de esta frontera, así como las mutaciones que ha sufrido desde su creación. Se profundiza, sobre todo, en la parte macedónica, es decir, la línea de separación entre Grecia, la ex Yugoslavia y Bulgaria.
\end{abstract}

\begin{abstract}
This article is a brief review of the ethnocultural, economic, and political implications which defined the northern border of Greece, established in 1913. It stresses the distinguishing features of this border, as well as the changes which it has undergone since its creation. Above all, it explores in depth the region of Macedonia, alog the border between Greece, what used to be Yugoslavia and Bulgaria.
\end{abstract}

La frontera norte de Grecia, trazada en gran parte en 1913, está ligada a la división del territorio balcánico, cedido por Turquía, entre los Estados nacionales que le sucedieron. La fisonomía de esa línea deriva principalmente del hecho que fue trazada en una zona balcánica impregnada del pluralismo cultural de los balcanes de antes de 1913. Su localización fue el origen de una serie de rasgos determinantes que vamos a tratar de hacer resaltar, así como sus mutaciones sucesivas. Profundizaremos, sobre todo, en la parte macedónica propiamente, es decir, la línea de separación entre la Macedonia hoy Grecia, la FYROM (Former Yougoslavian Republic of Macedonia/República de Macedonia ex Yugoslavia) y la Macedonia hoy Bulgaria:

* Este documento se presentó en el evento "Fronteras en perspectiva internacional", efectuado en la Universidad Autónoma de Baja California los días 17 y 18 de noviembre de 1997. Artículo traducido por Danielle Wynants.

** Geógrafa de la Universidad del Mar Egeo, Grecia. 


\section{DE LA FRONTERA NACIONAL A LA FRONTERA ETNO CULTURAL}

Al hablar de "Macedonia" se hace referencia a una vasta región de Europa del sureste que estuvo bajo la dominación otomana hasta 1912, que luego en 1913 se dividió entre Grecia, Serbia y Bulgaria (más o menos 3/6, 2/6 y $1 / 6$ respectivamente para cada uno de los tres Estados nacionales).

A partir del final del siglo XVIII, el mosaico etno-cultural que constituyen en ese entonces las poblaciones balcánicas, se sacude, se desmembra y se desgarra, tomado en la efervescencia nacionalista de ese periodo. El término "balcanización" fue característico de ese tipo de situación, que se usó para hacer referencia a otras complicaciones geopolíticas, como por ejemplo, la situación en el Líbano en los años ochenta. Cada una de las poblaciones de Macedonia buscaba entonces construirse y cristalizarse en una identidad nacional y acabaron en identificarse en Estados nacionales como son Grecia, Bulgaria, Rumania y Serbia. Por el contrario, los albaneses, de implantación masiva y muy antigua en la península, y a los que faltaba en esa época una referencia política-territorial, o sea, un Estado nacional albanés soberano, adoptaron otras banderas y combatieron para ellas, a pesar de que en 1913 se creó un Estado albanés independiente.

La división de Macedonia y las guerras anteriores y posteriores a ese acontecimiento dieron como resultado un nuevo mapa de las fronteras nacionales (entre Estados nacionales) en la región. A esas fronteras políticas tenían que corresponder las fronteras etno-culturales. Por ese hecho, el principio de nuestro siglo vio esfuerzos de "purificación étnica", que se manifestaron en masacres, intercambios y desplazamientos de poblaciones en gran escala (Gellner, 1983:98). Esos proyectos nacionalistas fueron complementados por ambiciosos proyectos de asimilación (Lafazani, 1993).

El trazo de la frontera que materializó la división de Macedonia en 1913 y que puso fin a las luchas nacionalistas abiertas, dio un golpe severo y quizás marcó el fin de las formaciones socioeconómicas rurales locales (Karavidas, 1978), con las cuales ya era completamente incompatible. Al mismo tiempo, los intercambios de las poblaciones que se hicieron después del trazado, han dado una homogeneidad religiosa asombrosa y pusieron fin a "la división cultural del trabajo y del espacio" (Vermeulen, 1984:225255; Stoianovich, 1960:234-313), la pequeña explotación mercante substituyó la economía de autosubsistencia, el crédito bancario ha concretizado la presencia de un Estado fuertemente centralizado. La división fronteriza de 1913 acabó con una ganadería trashumeante importante, misma que fue separada de los pastizales montañosos donde se desarrollaba, quedándose del otro lado de la frontera. 


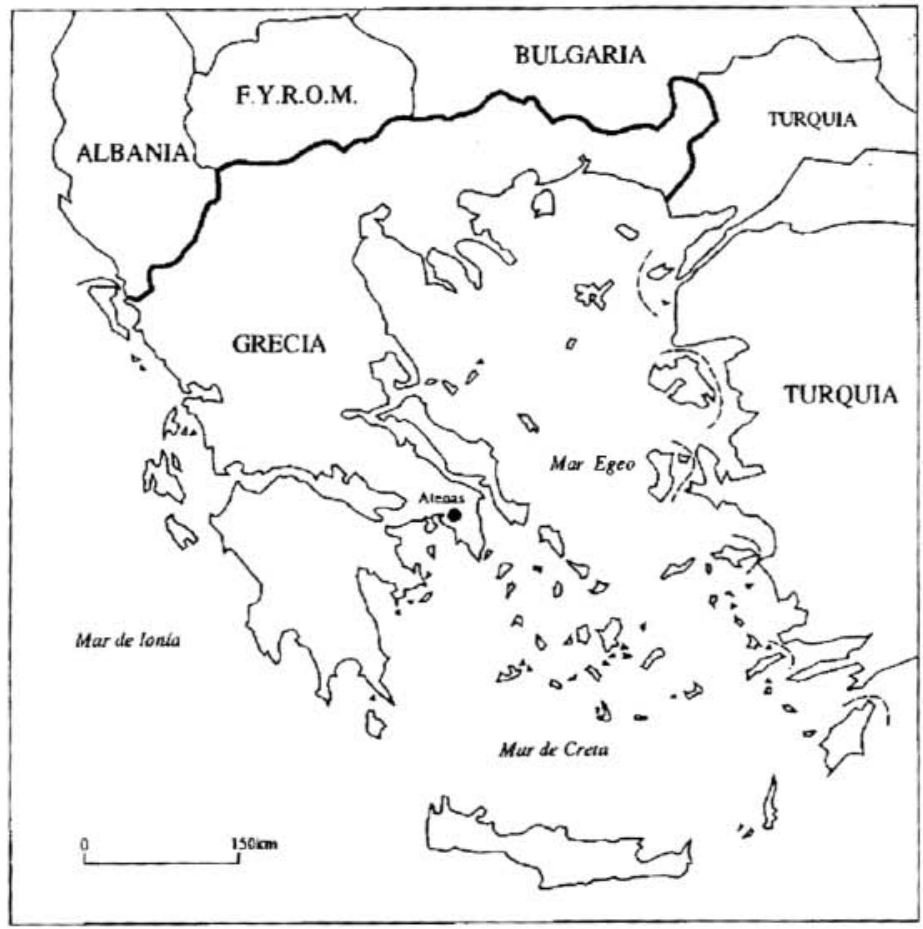

Figura 1.

Después de la unión de la mitad sureña de Macedonia en el Estado nacional griego, los significados de la pertenencia etno-cultural de la población debieron ser modificados seriamente, considerando el cambio de la coyuntura histórica e ideológica. Esa sociedad de ahora en adelante debía integrarse como la sociedad de un Estado con una identidad casi unidimensional $^{1}$, y al mismo tiempo, asumir los nuevos cortes y discontinuidades fronterizas a pesar del modo como el espacio socioeconómico macedónico había sido vivido hasta entonces, y de la afinidad y solidaridad cultural que se había dado con la población del otro lado de la frontera, así como su funcionamiento económico. Claro está que del otro lado de la frontera el hecho etno-cultural se desarrolló de la misma manera.

1 Comparar con el caso turco en Altan Gokalp (1986). Ver también Peter-Alford Andrews (1989). 
Hasta 1913, los grupos culturales se definían y distinguían entre ellos "étnicamente", el criterio principal era la pertenencia eclesiástica, y escn cialmente por oposición al grupo religioso dominante como lo son los turcos y los musulmanes. Además de las poblaciones judías concentradas en las ciudades, la ortodoxia cristiana agrupa a los griegos, los eslavos, los valaques (aromunes), los sarakatsanes, los gagauzes, los tsiganos cristianos, etcétera.

Ese sistema de organización cultural de la sociedad correspondía al mismo tiempo al concepto que la administración otomana tenía de la población que gobernaba. La adhesión religiosa fija los límites de los grupos culturales coherentes, y funciona como un sistema de líneas de demarcación que separa a los grupos locales. Límites que son válidos y se hacen sentir en todos los niveles, desde la periferia hasta el lejano corazón administrativo del imperio.

El sistema de fronteras (Shahrani, 1979) "étnicas" mencionado, fue particularmente claro y rígido, pero a la vez sinuoso hasta el extremo. Así pues, pudo separar minuciosamente las aldeas, e incluso separando a veces los barrios.

Por consecuencia, la nueva frontera nacional norte, trazada en 1913, tenía la posibilidad de reemplazar el embrollo de las fronteras "étnicas", y de marcar el fin de los conflictos nacionalistas que duraron mucho tiempo, y sobre todo, de materializar e imponer nuevos cortes y discontinuidades espaciales, administrativas y económicas que acababan de instaurarse por razones extralocales. Para ello, la nueva frontera ante todo debía de adquirir y revestir un contenido simbólico e ideológico, moverse y consolidarse progresivamente en frontera "etno-cultural". Dicho de otro modo, la nueva frontera de derecho no se conformaría en reemplazar la antigua línea de fronteras de hecho, sino que necesitaría, ella misma, convertirse en frontera de hecho, una frontera que cortaría Macedonia griega en vía de helenización, de la parte eslava, serbia o búlgara. Sin embargo, a pesar de los desplazamientos enormes y dramáticos ${ }^{2}$ de la población de y hacia la Macedonia griega, desplazamientos que apuntaron a la consolidación de esta frontera, su estabilidad y su carácter incontestable, las tensiones nacionalistas prácticamente nunca cesaron. Las mismas luchas nacionalistas siguieron adelante durante los dos grandes conflictos mundiales, tanto en la realidad como sobre el plan ideológico, para culminar más adelante, durante la guerra civil en Grecia (1946-1949).

\footnotetext{
2 A propósito de los intercambios de las poblaciones entre los países balcánicos, ver Shahrani (1979:140).
} 
Por último en el subconsciente colectivo, bien alimentado y manipulado por el discurso ${ }^{3}$ y la política oficiales, las luchas nacionalistas encontraron un terreno propicio.

\section{UNA FRONTERA NACIONAL CON GARANTÍAS INTERNACIONALES}

Al principio de los años cincuenta la frontera nacional norte se consolidó singularmente como sección de lo que teníamos la costumbre de llamar "la cortina de hierro", materializando la bipartición geoestratégica del mundo. Grecia, miembro de la OTAN, goza de las garantías militares frente a los diferentes países vecinos socialistas (of the Warsaw Pact, Pacto de Varsovia), una Bulgaria fiel a Moscú, una Yugoslavia rebelde y "no alineada" y una Albania aislada y solitaria. De ambos lados de la cortina de hierro prácticamente hermética y en el congelamiento obligatorio de las tensiones nacionalistas, cada uno de los países limítrofes procede, a su manera, a la realización de sus propios proyectos de integración nacional.

Sin embargo, Grecia, después de 1949, atizada por los americanos, tuvo que moderar sus relaciones con el régimen del Mariscal Tito, que tenía que ser reforzado en su oposición por Moscú. Ese hecho condujo a tranquilizar las tensiones nacionalistas en la sección greco-yugoslava de la frontera. En cambio, es al final de los años setenta que las relaciones greco-búlgaras mejorarona raíz de una perspectiva de adoptar una estrategia común frente a las minorías musulmanas viviendo en ambos países.

La entrada de Grecia en 1980 a la comunicad económica europea reforzó aún más el trazado de esa frontera poniendo el acento sobre su carácter de frontera que permite el intercambio de formaciones socioeconómicas diferentes y de regulador de los flujos de migrantes, de bienes y de información. Desde su trazado inicial en 1913, es después de la guerra que esa frontera llega a su impermeabilidad máxima, concretando así discontinuidades espaciales, sociales y económicas de las más insuperables, y separando no solamente dos países, sino los dos principales sistemas defensivos y socioeconómicos, correspondiendo a la bipartición geoestratégica del mundo, los dos mundos anteriores a la transición dẹ los regímenes socialistas iniciados en 1989.

3 A propósito del uso de la "cuestion de Macedonia" en la lucha anticomunista en Grecia, ver la tesis de Loanna Papathanasiou (1988:74). También, “...el comunismo fue una ideología eslava.." de Michael Herzfeld (1987). 


\section{DE LAS GARANTÍAS INTERNACIONALES A LA FRONTERA- BARRERA SOCIOECONÓMICA}

Después de la desaparición de la cortina de hierro entre el Occidente y los países del Este, acompañada de un dramático recrudecimiento de los viejos nacionalismos balcánicos, la frontera norte pierde rápidamente su carácter de "internacional" y vuelve a ser una frontera nacional, una línea bajo tensiones nacionalistas. Pero eso no parece ser más que la parte aparente del iceberg, ya que esa segunda vez, el contenido de esa frontera norte cambió radicalmente. He aquí porqué: El trazado de 1913, como lo hemos visto, recortó mucho más que un espacio geográfico; desmembró una unidad social y económica homogénea que funcionaba hasta entonces así, a pesar de o a causa de su pluralismo cultural. Desde 1913, los territorios cortados por la frontera evolucionaron de una manera totalmente diferente, bajo regímenes y sistemas socioeconómicos diametralmente opuestos. Y si podemos admitir que la ayuda americana hacia Grecia fue en parte compensada por una ayuda soviética análoga, pero que sólo concernía a Bulgaria, las digresiones de los índices económicos y del nivel de vida se profundizaron dramáticamente, sobre todo después de la asociación de Grecia a la comunidad europea y el debilitamiento simultáneo del campo socialista.

Así podemos concebir que la frontera norte recientemente representó, más que nunca, una línea de separación entre espacios socioeconómicos correspondiendo a niveles diferentes. Y ya que la vieja bipartición del mundo ya no es válida y que los países volvieron a hacer contactos más flexibles dictados por principios locales, esa frontera funciona actualmente como barrera que debe de contener tensiones económicas enormes, detener y acabar con las fuerzas que tienden a equilibrar y a homogeneizar a los balcanos, anulando las diferencias y los efectos de un recorte impuesto hace un poco más de ochenta años.

En esa ótica, la sociedad griega creyó sentirse suceptible de ser amenazada de reajustes económicos sucesivos y dolorosos, los cuales amenazaban con llevarla a perder progresivamente su adelanto material sobre las sociedades vecinas, acercándola a un promedio balcánico y alejándola al mismo tiempo de la unificación europea. En otros términos, en el momento de que Grecia trataba de mantenerse en la carrera europea ya difícil y penosa, fue atrapada por imperativos geohistóricos relacionados con su posición balcánica, sobre todo entre 1991 y 1995.

Sin embargo, esa nueva función de la frontera-barrera que teóricamente debía de proteger al país contra los flujos de migrantes-refugiados económicos que venían de los países ex socialistas (los cuales los griegos 
sabían que les hacían falta), le volvió a dar indirectamente un cierto significado internacional, ya que, al menos una formación pluriestatal, la unión europea, por el momento está directamente concernida por los indicios económicos en Grecia, así como por la gestión de su mercado de trabajo y de la mano de obra. Esa manera de resentir por parte de sus vecinos la amenaza de una baja en el nivel de vida, ligada a la crisis económica generalizada que golpea varios países, volvió a animar en Grecia una corriente nacional-populista, llevándola, al mismo tiempo, a reafirmar muy claramente su adhesión a la unión europea, de manera paralela a la insistencia de una frontera que Grecia quiere garantizar por conducto de la unión europea, constatamos un regreso a una frontera con tensión étnica, anacronismo incompatible con la adhesión a Europa en vía de integración, pero comprensible en su contexto balcánico.

Hoy, con la presión del mundo de las empresas y de las finanzas, las ideologías nacional-populistas parece más bien perder el paso en provecho de una frontera que se quiere permeable y fuente de provecho. Así es que el espacio balcánico, tantas veces fragmentado y dividido, da la impresión de exigir un regreso a una integridad económica con la minimización del peso de esa frontera, arbitrariamente impuesta hace un poco más de ochenta años, pero que más y más se vuelve a poner a discusión por las leyes del mercado.

\section{BIBLIOGRAFÍA}

ANDREWS, Peter-Alford (ed.). 1989. Ethnic Groups in the Republic of Turkey, Wiesbaden, Ludwig Reichert Verlag, $670 \mathrm{p}$.

GELLNER, Ernest, 1983. Nations and Nationalism, Oxford, Blackwell.

GOKALP, Altan. 1986. Turquía en transición: disparidades, identidades, poderes, París, Maisonneuve y Larose, $217 \mathrm{p}$.

HERZFELD, Michael. 1987. Anthropology through the Looking Glass: Critical Ethnography in the Margins of Europe, Cambridge, Cambridge University Press.

KARAVIDAS, K.D. 1978. Agrotika, meleti syngritiki (De la paysannerie: étude comparative), Atenas, Papazisis, 1a. edición, 1931, 700 pp.

LAFAZANI, Dora. 1993. "Adhesión cultural y diferenciación social en la cuenca del bajo-Strymon: estudio de integración nacional en una región macedónica", tesis de doctorado, París IV-Sorbonna.

PAPATHANASIOU, Ioanna. 1988. Contributión à l'historie du Parti Communiste Grec, 1949-1951, Tesis de doctorado, Universidad de 
París X-Nanterre, bajo la dirección de Annie Kriegel e Ilios Yannakakis, octubre.

SHAHRANI Nazif Mohib M. 1979. The Kirghiz and Wakhi of Afghanistan: Adaptation to Closed Frontiers, The University of Washington Press.

STOIANOVICH, Trajan. 1960. "The Conquerring Balkan Orthodox Merchant”, en Journal of Economic History, núm. 20.

VERMEULEN, Hans. 1984. "Greek Cultural Dominance Among the Orthodox Population of Macedonia During the Last Period of Ottoman Rule", en A. Blok and H. Driessen (editores), Cultural Dominance in the Mediterranean Area, Universidad Católica de Nijmegen, (Vakgroep Culturele Antropologie, 16). 